\title{
THE IMPACT OF SOCIAL LIFE STYLE ON MID-FACE FRACTURE
}

\author{
Hala R. Ragab*
}

\begin{abstract}
Introduction: Mid face trauma, with or without life threatening injuries needs accurate assessment which should be in a systematic and repeated manner.
\end{abstract}

Aim of the work: Is the identification of such injuries and the definitive management of common injury patterns that were changes laterally due to the advancement and severity of social life style.

Patients and Methods: the study performed from January 2016 to December 2018 (36 months) on 288 adult patients with mid-face trauma, at Oral and Maxillofacial Department, Faculty of Dentistry, Alexandria University.

Results: Patients demographic data demonstrated that road traffic accident, motor vehicle, is the major etiological factor that change the pattern of mid-face fractures due to change of economic and social life style.

Conclusion: The rapid change of the economic and social life style was reported as the leading cause of pattern change of mid-face trauma. RTAs were the main cause of fractures followed by falls and sport respectively.

KEYWORDS: Mid-face fracture, change the pattern of fracture, road traffic accident, modification of Le Fort fracture.

\section{INTRODUCTION}

Trauma of the facial region predisposes injuries to hard (skeleton and dentition) and soft tissues ${ }^{(1)}$.

The mid-face is composed of: two maxillary bones, two nasal bones, two palatine bones, two zygomatic bones, two zygomatic process of temporal bone, two lacrimal bones, two inferior conchae and pterygoid plates of sphenoid, vomer, ethmoid and its attached conchae ${ }^{(2)}$.

Fracture pattern may vary with behavior of injury, anatomy of the site of injury and direction of the affected impact force ${ }^{(3)}$.

* Assistant Professor of Oral and Maxillofacial Surgery, Faculty of Dentistry, Alexandria University. 
Injuries of the mid-face region are increasing in frequency and severity because of excessive credence on road transportation and high population social and economic life style of the population. The road traffic accidents considered to be the primary cause of mid-face fracture followed by falls, assaults and sports ${ }^{(4)}$.

\section{AIMS AND OBJECTIVES}

The objective of the present study was to evaluate the impact of socioeconomic changes on mid-face fractures in Alexandria region, and to determine the relationship between mechanism of injury and fracture patterns.

\section{PATIENTS AND METHODS}

A retrospective study was performed between January 2016 and December 2018 (36 months) on 288 adult patients with mid-face fractures. The patients were transferred from Emergency Department in Alexandria University.

The diagnosis of the fracture is based on:

a) Complete history: the mechanism and velocity of injury.

b) Subjective symptoms e.g. pain, numbness, diplopia, nasal discharge or trismus.

c) Clinical examination: included the mid-face,

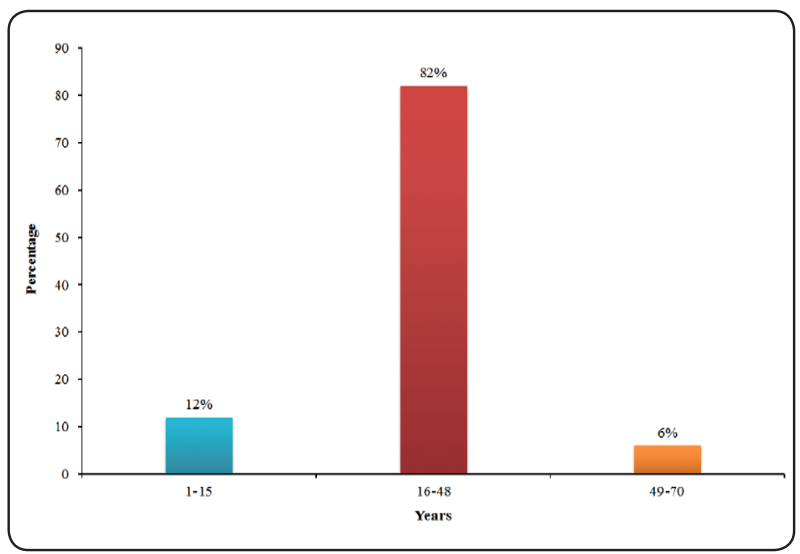

Fig. (1): Age distribution
ENT, neurosurgical and ophthalmologic examination.

d) Radiological examination included plain $\mathrm{x}$-ray, craniocelebral CT scanning, and three dimensional CT reconstruction.

In our study 288 patients with middle face fractures in ratio of $83 \%$ males and $17 \%$ females. The age distribution showed the most involved age was $16-48$ years $(82 \%), 1-16$ years $(12 \%)$ and $49-70$ years $(6 \%)$ (Figure 1).

Etiologic factors were classified as road traffic accidents (caused by cars and motorcycles) (93\%), fall from height (due to the increase in high-rise buildings height) (5\%) and sport injuries (2\%) (Figure 2).

There were multiple fractures (48\%), nasal bone fractures $(22 \%)$, zygoma fractures $(12 \%)$, maxilla fractures $(10 \%)$, and orbital floor fractures $(8 \%)$ (Figure 3).

\section{Surgical approaches}

Dealing with the patients through application of basic life support (i.e. airway, breathing, circulation). Stablish the airway by the chin-lift jaw thrust maneuver, oro-pharyngeal airway, and clearing the airway of foreign bodies. In unconscious patients, Oro-tracheal intubation was required. Controlling the hemorrhage with direct pressure, and insertion

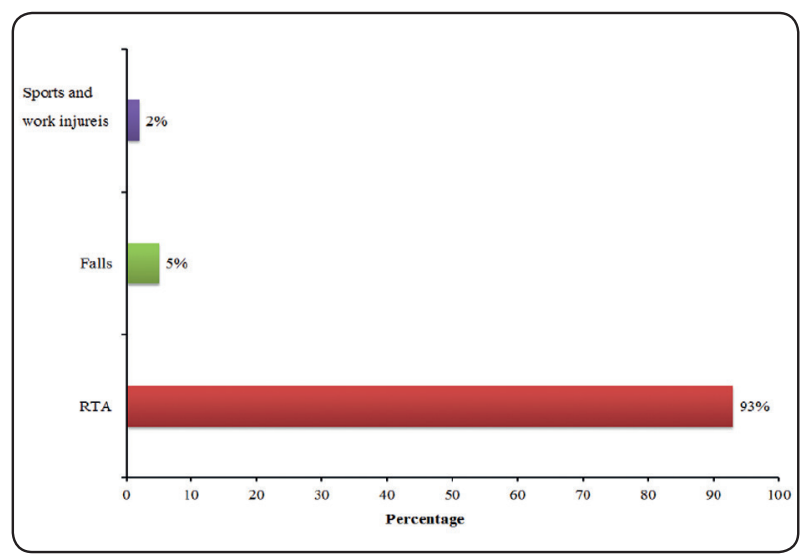

Fig. (2): Etiology of trauma. 


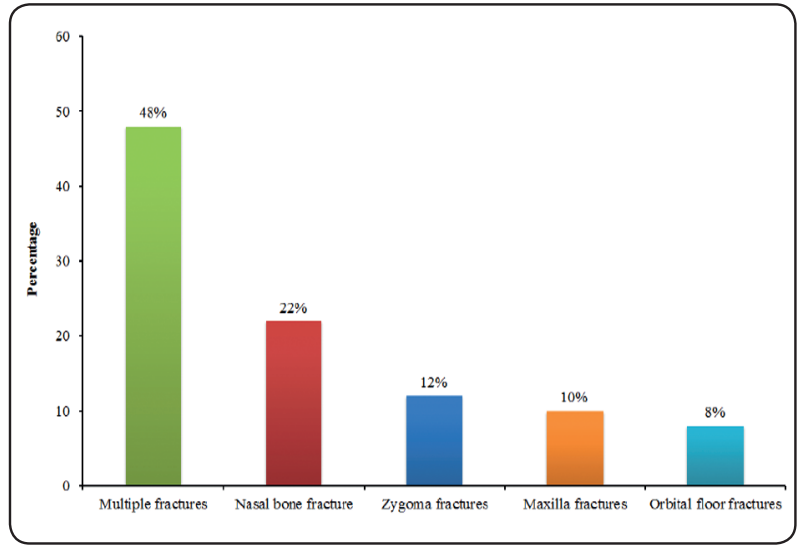

Fig. (3): Pattern of maxillofacial fractures. of wide pore IV canula for infusion of IV fluids and/or blood components. Laboratory tests were ordered (CBC, serum electrolytes and liver function tests). Evaluation of brain injuries; the level of consciousness was measured by Glasgow coma scale (GCS), and pupillary function.

Treatment was usually delayed until other more serious life-threating injuries have been addressed. Co-management between maxillofacial surgeon, neurosurgeon, ophthalmologist and anesthesia team was carried out.

\section{Examples of the current cases}
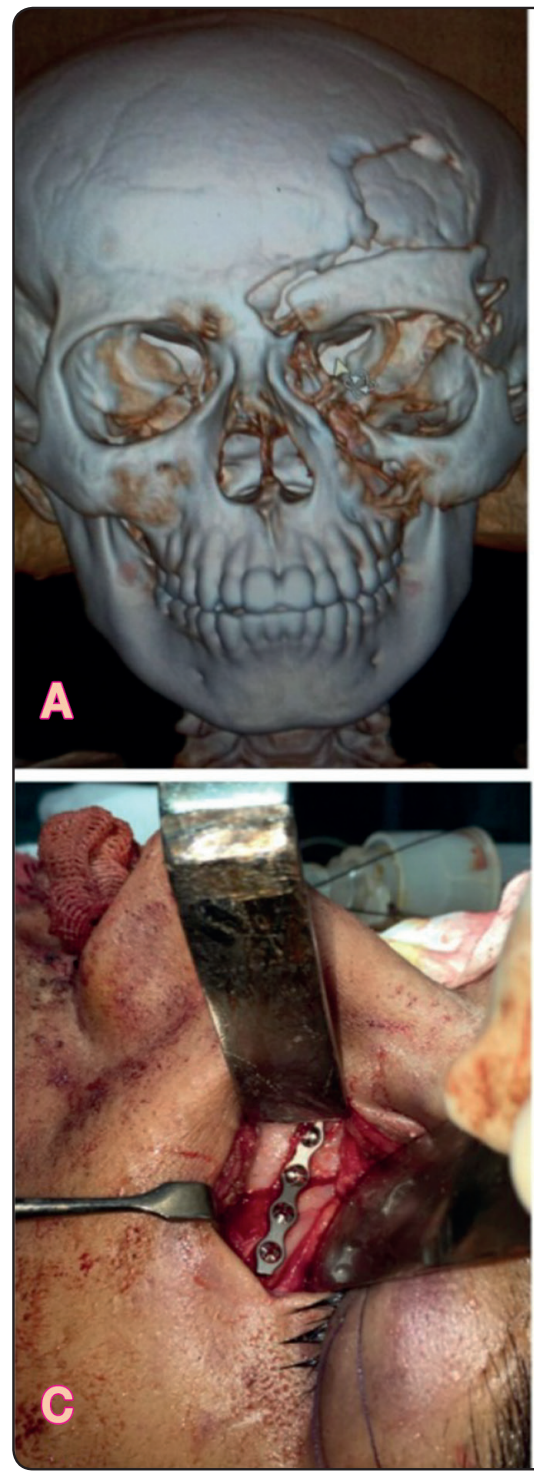
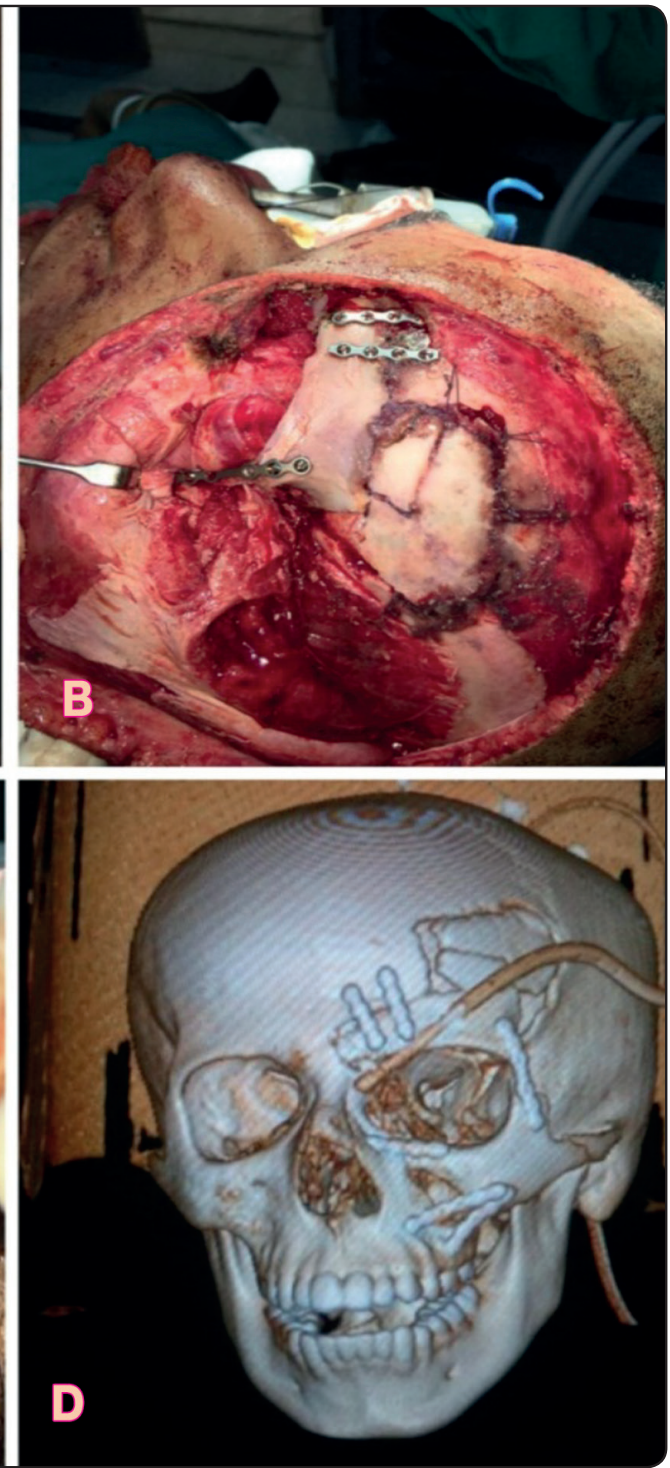

Fig. (4): Case 1: (A) Male patient 31 years old with extensive midface trauma due to road traffic accident. $\mathrm{He}$ presented with compound comminuted fracture of frontal bone, frontal sinus, detachment of fronto-orbital bar, fracture zygomaxillary bone, and fracture nose. (B) Coronal flap and fixation of the comminuted bones with miniplates. (C) Fixation of the maxilla with titanium miniplates (D) post operative 3D CT showing reduction and fixation of the fractured bones. 

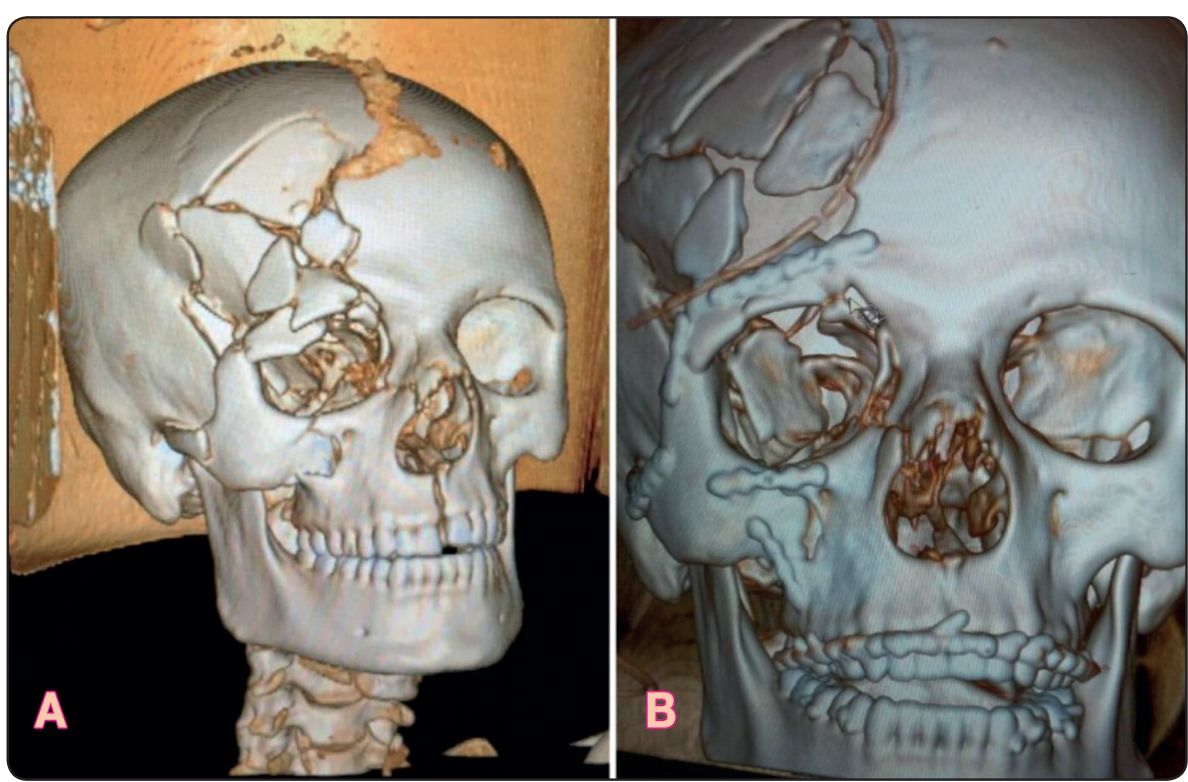

Fig. (5): Case 2: (A) Male patient 55 years old presented with comminuted fracture of the cranium, high periorbital comminuted fracture, depressed fracture infra-orbital rim and orbital floor. (B) The treatment was done from the fixed bone to the mobile bone and from up to down by fixation of the comminuted bone with titanium miniplates to restore the function and esthetic.

\section{DISCUSSION}

The epidemiologic features and mechanism of maxillofacial fractures are varied between different countries according to cultural, social and political factors ${ }^{(5)}$.

Road traffic accidents (RTAs) have fallen in developed countries, while continue to rise with horrifying speed in the low-and middle- income countries of Africa and Asia ${ }^{(6)}$. The reductions in RTAs in developed countries are largely attributed to different factors like road safety measures such as seat belt use, traffic calming measures and traffic law enforcement ${ }^{(7)}$.

In developing countries, there are many reasons of higher frequency of RTAs: inadequate road safety awareness, unsuitable road conditions, there is no expansion of the motor way network, no safety features, not wearing seat belts or helmets ${ }^{(8,9)}$.

Two wheelers were responsible for the majority of road traffic accidents. Two wheelers are very popular method of transportation because of fuel efficiency and easier to use in congested traffic ${ }^{(10)}$. In our study the most frequent etiology was road traffic accidents (93\%), followed by falls (5\%) and sport and work injuries (2\%), the age distribution showed the most involved age was 16-48 years (82\%), followed by $1-15$ years (12\%) and $49-70$ years $(6 \%)$.

The typical three classes of weak lines of the mid-face fracture have been described by Rene Le Fort in $1901^{(5,6)}$. The mid-face fractures were found to be more complex than those produced by Le Fort. A modified Le Fort fracture classification includes subdivision to cover the complex pattern of mid face fractures ${ }^{(11-12)}$.

Le Fort I (low-maxillary fracture): This is a horizontal fracture in the body of maxilla that results in detachment of a tooth bearing segment from the rest of maxillary body.

Le Fort I a: Law maxillary fracture multiple segments.

Le Fort II (pyramidal fracture): In this fracture the maxilla will be separated from the base of the skull by fractures of the nasal bone and the frontal processes of the maxillae.

Le Fort II a: Pyramidal and nasal fracture.

Le Fort II b: Pyramidal and naso-orbioethmoidal (NOE) fracture. 
Le Fort III (Cranio facial disjunction): It separates the middle third of the face from the cranium.

Le Fort III a: craniofacial disjunction and nasal fracture.

Le Fort III b: craniofacial disjunction and NOE.

Le Fort IV: Le Fort II or III and cranial base fracture.

Le Fort IV a: Supraorbital rim fracture.

Le Fort IV b: Anterior fossa and supraorbital rim fracture.

Le Fort IV c: Anterior cranial fossa and orbital wall fracture.

The original Le Forts and its modification provided surgeons with reference points of stability, but still does not allow for description of segmental and comminuted fractures or bone loss ${ }^{(11,13,14)}$.

The nose was the most common isolated midface zone affected by trauma followed by the maxilla ${ }^{(15,16)}$. In this study, multiple fractures came first $(48 \%)$, then nasal bone fracture $(22 \%)$, zygoma fractures (12\%), maxilla fractures $(10 \%)$, orbital floor fractures $(8 \%)$ in a descending order of incidence.

In all mid-face fractures, the fixation of buttresses of the facial skeleton was done first to provide support for the maxilla ${ }^{(17,18)}$. In pan facial fractures, mid-face fractures in combination with upper face and/or mandible fractures, Gruss and Philips $1989^{(19)}$ recommend the reconstruction of pan facial fractures should processed from the stable fractures to the unstable ones. The fixation of cranial fractures, followed by repair of the zygomatic arch and zygomatic body. The next fixation is the central facial skeleton, nasoethmoid region and infraorbital rims (Le Fort II level), followed by the Le Fort I level fixation. This was our protocol in management of the pan facial trauma.

According to Markowitz and Manson $1989^{(20)}$ the repair should begin in the central zone: mandible palate and nasoehtmoidal fractures, then followed by repair of the lateral zone: the zygomatic arch and body fractures and finally Le Fort I level fracture to repair the occlusion.

The reconstruction in our study begin in the stable fractures then followed by the unstable ones, fixation of sizable segmental fractures then the small segmental ones, fixation of buttresses, and finally insertion of bone grafts.

Surgical exposure of mid-face include ${ }^{(21,22)}$ :

a. Intra oral: buccal sulcus, marginal rim and cold well- Luc sinus approach.

b. Extra oral: subciliary incision, brow incision, coronal and bicoronal flap, Mid face degloving, and Gillies approach.

In our study most patients were those of compound pattern where soft tissue injury and skin detachment provided obligatory surgical approaches for mid face. We delayed bone fixation, while emergency skin approximation was undertaken and edema subside (3-7 days) to provide sound skin closure over the fixated bone.

\section{CONCLUSIONS}

Lately, the pattern of mid-face trauma has been changed due to the rapid and aggressive change of the socioeconomic life style. The Modification of Le Fort Fracture required a modified classification includes subdivision to cover the complex pattern of mid-face fractures. The increasing number of motor vehicle accidents may be attributed to many factors such as fast and slow-moving vehicles; large numbers of motorcycles, scooters and mopeds; low driving standards; large number of over loaded buses; wide spread disregard for traffic rules; and poor street lighting. Vehicles that have 2 wheels, such a bicycles and motor cycles are less stable than cars and provide little protection to drivers in accidents.

Improved education about road safety may decrease the incidence of motor vehicle accidents. 


\section{REFERENCES}

1. Chandra Shekar BR, Reddy C. A five - year retrospective statistical analysis of maxillofacial injuries in patients admitted and treated at two hospitals of Mysore city. Indian J Dental Res. 2008;19:304-8.

2. Agnihotri A, Galfat D, Agnihotri D. Incidence and pattern of maxillofacial trauma due to road traffic accidents: A prospective study. J Maxillofac Oral Surg. 2014;13:184-8.

3. Bali R, Sharma P, Garg A, Dhillon G. A comprehensive study on maxillofacial trauma conducted in Yamu manager, Indian. J Inj Violence Res. 2013;5:108-16.

4. Mohem D. Transportation Research and Injury prevention program (TRIPP). Bulletin. 2006; 3:1-2.

5. El Arabi MS, Bataineh AB. Changing pattern and etiology of maxillofacial fractures during the civil uprising in western Libya. Med Oral Pathol Oral Cir Bacal. 2018;23:e 248-55.

6. Ansari MH. Maxillofacial fractures in Hamedan province, Iran a retrospective study (1987-2001). J Craniomaxillofac Surg. 2004;23:28-34.

7. Tripude BH, Naik RS, Anjan Kar AJ, Khajuria BK. A study of the pattern of cranio-cerebral injuries in road traffic accident. J Indian Acad Forensic Med. 1998;20:9-12.

8. Adeyemo WL, Ladeinde AL, Ogunlewe MO, James O. Trends and characteristics of Oral and Maxillofacial injuries in Nigeria; A review of the literature. Head face Med 2005;1:7.

9. Brasilerio BF, Passeri LA. Epidemiologic analysis of maxillofacial fractures in Brazil; A 5 years prospective study. Oral Surg Oral Med Oral Pathol Oral Radiol Endod. 2006;102:28-34

10. Manson PV, Hoopes JE, Su CT. Structural Pillars of the facial skeleton; AM approach to the management of Le fort fractures. Plast Rconstr Surg. 1980;66:54-62.

11. Patil RS, Kale TP, Kotra Shetti SM, Baliga SD, Prabhu $\mathrm{N}$, Issrani R. Assessment of changing patterns of Le fort fracture lines wing computed Tomography scan; an observational study. Acta Odontol Scand. 2014;72:984-8.

12. Rheo JT, Novelline RA. How to simplify the CT diagnosis of Le Fort fractures. Am J Roentgenol. 2005;184:1700-5.

13. Kamath RA, Bharani S, Hammannavar R, Ingle SP, Shah AG. Maxillofacial trauma in central Karnataka, India: an outcome of 95 cases in a regional trauma care centre. Craniomaxillo Facial Trauma Reconstr. 2012;5:197-204.

14. Septa D, Newaskar UP, Agrawa D, Tibra S. Etiology, incidence and patterns of mid-face fractures and associated ocular injuries. J Maxillofac Oral Surg. 2014;13:115-9.

15. Sargent LA. Nasoethmoid orbital fractures diagnosis and treatment. Plast Reconstr Surg. 2007;120(Suppl 2):165315 .

16. Sheltom D. Nasal-orbital - Ethmoid fractures. In: Alling CI, Osbon D, (eds). Maxillofacial trauma. Philadelphia, Lea and Febiger, 1988, pp 363-71.

17. Mc Rae M, Frodel J. Midface fractures. Facial Plast Surg. 2000;16:107-13.

18. Stanley R. Treatment of orbitozygomatic fractures. In: Holck DE, (ed). Facial plastic and Reconstructive surgery. $2^{\text {nd }}$ ed. New York, Thieme Medical, 2003.

19. Gruss J, Phillips J. Complex facial trauma; the evolving role of rigid fixation and bone graft reconstruction. Clim Plast Surg. 1989;16:93-105.

20. Markowitz B, Manson P. Panfacial fractures organization of treatment. Clim Plast Surg. 1989;16:105-14.

21. Balakrishman K, Ebenezer V, Dakir A, Kumar S, Prakash D. Management of tripoo fractures (zygomaticomaxillary complex) 1 Point and 2 Point fixation: A 5-year review. J Pharm Bioallied Sci. 2015; 7(Suppl 1): S242-7.

22. Gassmer R, Tuli T, Hachl O, Rudisch Ulmer H. Craniomaxillofacial trauma; a 10 year review of 9,543 cases with 21, 067 injuries. J Cranio Maxillofac Surg 2003;31:51-61. 